\title{
Selection component analysis of the PGI polymorphism in Sphaeroma rugicauda
}

\author{
D. J. Heath, \\ B. J. Riddoch, \\ D. Childs and \\ J. R. Ratford
}

\author{
Department of Biology, University of Essex, \\ Colchester, U.K. \\ * Department of Human Sciences, \\ University of Loughborough, \\ Loughborough, U.K.
}

Genotype frequencies in samples of males, sterile females, fertile females and random offspring were used to determine whether natural selection was acting on a diallelic phosphoglucose isomerase polymorphism. There was some evidence that female participation in reproduction depended upon genotype. The most consistent and significant effect was that the frequency of alleles transmitted from males to offspring varied with the genotype of the mother. The direction of this effect was such as to maintain both alleles in the population.

\section{INTRODUCTION}

Although the action of natural selection on morphological variants is well documented, there is much less evidence for its effect on biochemical variation (Endler, 1986), despite the intensive investigations of the past 20 years. This may merely reflect the fact that biochemical variation is neutral or subject to only very weak selection but it could arise from an observational bias which Endler identifies. Most studies of fitness differences have concentrated on mortality rather than on reproductive components such as fertility, mating ability and gametic viability. This is not surprising perhaps, given the practical difficulties associated with identifying these differences in natural populations, but what evidence there is leads Endler (p.155) to conclude that "reproduction related selection may be a powerful and heretofore underestimated factor in evolution".

Sampling and statistical techniques have been developed for selection component analysis (SCA) which allow at least some of the reproductive components of fitness to be estimated (Christiansen and Frydenberg, 1973). These techniques provide an analysis of fecundity, sexual, gametic and zygotic selection using a sample of males, sterile females, fertile females and their offspring. Although the method confounds some components and is insensitive to certain sorts of effects it has been applied successfully to biochemical polymorphisms in a variety of organisms; Drosophila
(Bungaard and Christiansen, 1972), barley (Hordeum) (Clegg et al., 1978), the fish Zoarces viviparus (Christiansen et al., 1973), the deer Odocoileus virginianus (Baccus et al., 1977) and the deer mouse Peromyscus maniculatus (Nadeau and Baccus, 1981). In all of these studies there was evidence of natural selection, with reproductive components more frequently implicated than mortality. The only case where there was no evidence for fitness differences was the study by Siegismund (1985) of biochemical variation at two loci in the marine amphipod Gammarus oceanicus. Given the promising nature of these results there is clearly a need to assess their generality by extending this technique to a variety of organisms and gene loci.

The estuarine isopod Sphaeroma rugicauda lends itself to this type of analysis because of its biological characteristics. It has an annual life cycle, a short breeding season, males and females form precupulas and females are viviparous (Heath and Khazaeli, 1985). Previous work on a diallelic polymorphism at the phosphoglucose isomerase (PGI) locus suggested that there was a stable polymorphism influenced by selection (Edwards and Heath, 1983). We therefore undertook a much more detailed selection component analysis of this system.

\section{METHODS}

The population studied has been described elsewhere (Heath and Khazaeli, 1985; Edwards and 
Heath, 1983) as has the genetic basis of the polymorphism.

In 1982-1984 samples were taken from the population after mating but before any offspring had been released. Males were deep frozen immediately and subsequently electrophoresed for their PGI genotype using the method of Edwards (1981). Females which lacked oostegites (immature females), i.e., those which had not undergone a pre-reproductive moult and hence could not have been fertilised, were treated similarly. Mature females were kept individually in petri dishes of seawater. If no offspring had been released within 6 weeks the female was classed as sterile and genotyped. All the offspring of fertile females were counted and the genotype of one random offspring and of the mother determined. Prior to electrophoresis the body length of fertile females was measured. This gives genotype frequencies in males, non-fertile (immature and sterile) females, fertile females and one random offspring per female. Mean numbers of offspring (brood size) for females of different genotypes can also be estimated.

These data are used in the selection component analysis which consists of a logical sequence of six interdependent tests (table 1) corresponding to individual selection components.

$T_{6}$ also requires that there is no difference in fecundity between genotypes; this latter test has to be carried out independently of the above sequence. In addition the overall fit of the data to a model of neutrality and random mating can be examined.

Some additional data were gathered in 1981 and 1985 which will also be presented. In 1981 these consisted of genotype frequencies in fertile females and one random offspring. In 1985 several random offspring from each fertile female were electrophoresed. No data were obtained in either of these years on males or on non-fertile females.

\section{RESULTS}

\section{Fecundity}

Fig. 1 shows the mean numbers of offspring (brood size) for females of each genotype for the years 1982-1984, the data being grouped into five size classes of female. This indicates a clear positive relationship between female size and brood size in all three years, but no systematic relationship between genotype and brood size.

This interpretation is confirmed by a three-way analysis of variance (table 2) which shows a highly significant difference in brood size between female size classes, but no differences between genotypes. There is also a significant difference in brood size between years, which is primarily due to a significant difference in female size between years.

\section{Selection component analysis}

The results are given in tables 3 and 4 . Table 3 shows for each year the observed numbers of each genotype amongst males, sterile females, fertile females and one random offspring per female. The numbers in italics are the expected numbers calculated on the basis of random mating and the absence of all selection. The results of the accompanying statistical analysis are given in table 4 which shows three significant departures from expectation. In both 1983 and 1984 the frequency

Table 1

\begin{tabular}{|c|c|c|c|}
\hline Test & Hypothesis & $\begin{array}{l}\text { Possible effects } \\
\text { leading to rejection }\end{array}$ & Restrictions \\
\hline$T_{1}$ & $\begin{array}{l}\text { Half offspring of heterozygous mothers are } \\
\text { heterozygotes }\end{array}$ & $\begin{array}{l}\text { Differences in gametic or zygotic } \\
\text { viability }\end{array}$ & None \\
\hline$T_{2}$ & $\begin{array}{l}\text { Frequency of alleles transmitted via male gametes } \\
\text { independent of female genotype }\end{array}$ & $\begin{array}{l}\text { Non random mating. Female } \\
\text { genotype specific differences in } \\
\text { gametic or zygotic viability. }\end{array}$ & $H_{1}$ must be granted \\
\hline$T_{4}$ & $\begin{array}{l}\text { Equal genotype frequencies in fertile and non- } \\
\text { fertile females }\end{array}$ & $\begin{array}{l}\text { Differential mating success in } \\
\text { females }\end{array}$ & None \\
\hline$T_{5}$ & $\begin{array}{l}\text { Equal genotype frequencies in adult males and } \\
\text { females }\end{array}$ & $\begin{array}{l}\text { Unequal zygotic selection in two } \\
\text { sexes }\end{array}$ & $\begin{array}{l}\mathrm{H}_{1}, \mathrm{H}_{2}, \mathrm{H}_{3}, \mathrm{H}_{4} \text { must } \\
\text { be granted }\end{array}$ \\
\hline$T_{6}$ & $\begin{array}{l}\text { Adult population equals estimated zygote } \\
\text { population }\end{array}$ & Zygotic selection & $\mathrm{H}_{5}$ must be granted \\
\hline
\end{tabular}


Relationship between size class, genotype and fecundity in successive breeding seasons. (Numbers within bars represent the sample size for that size class).
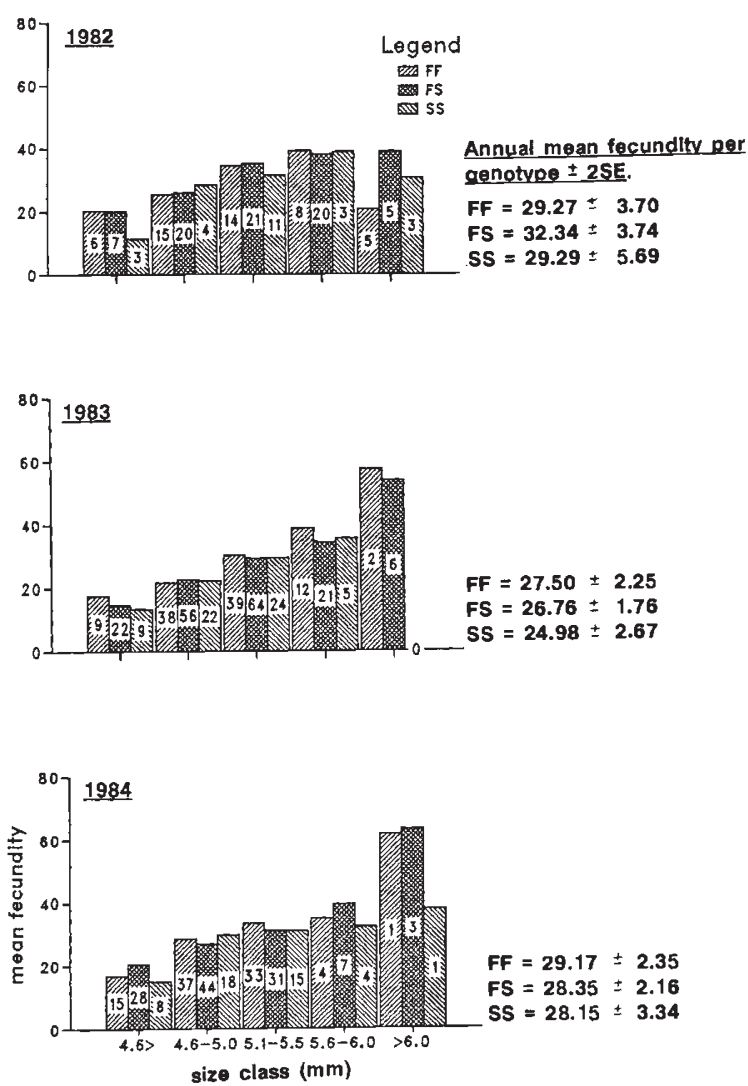

Figure 1 Mean number of offspring for each genotype, 19821984.

of alleles transmitted in male gametes was not independent of female genotype. In addition in 1983 genotype frequencies were different amongst fertile and non-fertile females. The total fit of the data to a model of neutrality and random mating showed no significant depature in any of the three years although the figure for 1983 approaches significance (critical value $=16 \cdot 919$ ).

The direction of these effects can be seen in table 3 , by comparing the observed and expected numbers. The unequal transmission rate of male alleles through females of different genotypes in 1983 and 1984 arises from two sources. First, a deficiency of FF offspring compared with FS offspring in FF mothers and secondly an excess of FF offspring and a deficiency of SS offspring in FS mothers, the latter pattern being weakly repeated in 1982. Thus the deviations are consistent in the two years which yielded a significant test result. The significant result for female sexual selection in 1983 arises from an excess of FF and a deficiency of SS among the non-fertile females. This pattern appears in 1982 and also very weakly in 1984.

If the population is assumed to be in equilibrium, then following Christiansen et al. (1973) it is valid to pool the data for all three years. Male genotype frequencies in the samples in table 3 are homogeneous over the three years, as are both female genotype frequencies and offspring genotype frequencies. This gives us no reason to reject the hypothesis of equilibrium, indeed the genotype frequencies presented here are very similar to those described by Edwards and Heath for 1978 and 1979. When the data are pooled (tables 3,4 ) the pattern described earlier still persists.

$T_{2}$ yields a highly significant departure from expectation (table 4), implying that transmission of alleles via male gametes is not independent of female genotype. SS mothers produce offspring genotype numbers as expected (table 3 , pooled) but there are marked deviations for FS and SS mothers, in the directions already described. $T_{4}$ is still significant, with more FF females and fewer SS females than expected in the non-fertile category. The total fit to neutrality and random mating is now very poor (table 4).

There is very clear evidence from these data for consistent fitness differences, the most marked effect being the distortion of offspring ratios in FF and FS females. The frequencies of paternal alleles in the offspring of females of different genotypes can be extracted from the data in table 3 . These frequencies are shown in table 5 which includes the extra data from 1981 and 1985. Paternal F alleles have their highest frequencies in progeny of FS females and their lowest frequencies in progeny of FF females. Their frequencies in progeny of SS females are intermediate. In 1983 and 1984 paternal $F$ allele frequencies are significantly heterogeneous between female genotypes. The data from the smaller samples of 1981 and 1982 are consistent with this but show no significant heterogeneity. The data for 1981-1984 are homogeneous $\left(\chi^{2}=4.73,6 \mathrm{df}\right)$ and can be pooled (table 5 , column 5 ). There is then a highly significant heterogeneity in $F$ allele frequency transmitted through the three female genotypes. The data for 1985 , based on genotyping more than one offspring per female, are again highly heterogeneous with male $F$ alleles transmitted at higher frequencies through FS females. Table 5(b) also contains data on estimated $\mathrm{F}$ allele frequencies in males in 1982- 
Table 2 Three way analysis of variance of brood size on year female size and genotype

\begin{tabular}{|c|c|c|c|c|}
\hline Source of variation & SS & df & MS & $F$ \\
\hline \multicolumn{5}{|l|}{ Main effects } \\
\hline Year & $2067 \cdot 96$ & 2 & $1033 \cdot 98$ & $10 \cdot 723 * * *$ \\
\hline Size & $30132 \cdot 18$ & 4 & $7533 \cdot 05$ & $78 \cdot 125^{* * *}$ \\
\hline Genotype & 183.47 & 2 & 91.74 & $0 \cdot 195$ \\
\hline \multicolumn{5}{|l|}{ 2-way interactions } \\
\hline Year $\times$ size & $4084 \cdot 99$ & 8 & $510 \cdot 62$ & $5 \cdot 296 * * *$ \\
\hline Year $\times$ genotype & $108 \cdot 25$ & 4 & $27 \cdot 06$ & $0 \cdot 281$ \\
\hline Size $\times$ genotype & 893.90 & 8 & $111 \cdot 74$ & $1 \cdot 159$ \\
\hline \multicolumn{5}{|l|}{ 3-way interactions } \\
\hline Year $\times$ size $\times$ genotype & $1431 \cdot 81$ & 15 & $95 \cdot 45$ & 0.990 \\
\hline Residual & $65470 \cdot 84$ & 679 & $96 \cdot 422$ & \\
\hline Total & $105486 \cdot 75$ & 722 & $146 \cdot 104$ & \\
\hline
\end{tabular}

*** $P=<0.001$.

Table 3 Observed numbers and genotypes of males, fertile and non fertile females and random offspring

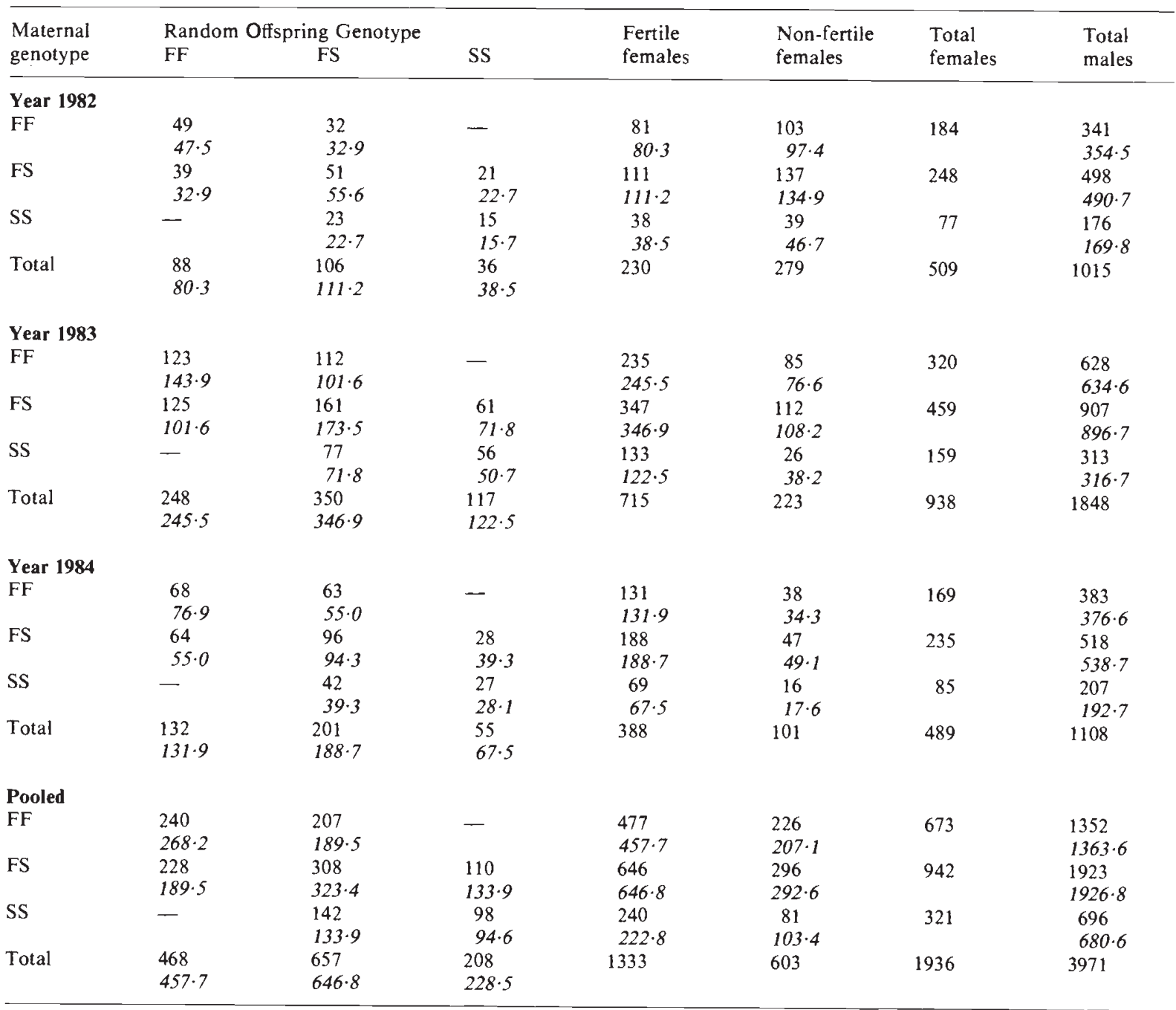


Table 4 Statistical tests of Table 3

\begin{tabular}{llllll}
\hline & & & \multicolumn{3}{c}{$\chi^{2}$} \\
Test & df & 1982 & 1983 & 1984 & Pooled \\
\hline$T_{1}$ & 1 & 0.730 & 0.901 & 0.085 & 0.697 \\
$T_{2}$ & 2 & 0.326 & $9 \cdot 126^{*}$ & $7 \cdot 141^{*}$ & $14 \cdot 757^{* * *}$ \\
$T_{3}$ & 1 & 0.998 & 0.005 & 0.280 & 0.579 \\
$T_{4}$ & 2 & 0.658 & $6.306^{*}$ & 0.581 & $7 \cdot 125^{*}$ \\
$T_{5}$ & 2 & 1.312 & 0.01 & 0.375 & 0.668 \\
$T_{6}$ & 1 & 0.190 & 0.231 & 1.557 & 0.013 \\
Total fit to & & & & & \\
neutrality & 9 & 4.214 & 16.57 & 10.019 & $23.839^{* *}$ \\
\hline
\end{tabular}

${ }^{*} P=<0.05 ;{ }^{* *} P=<0.01 ;{ }^{* * *} P=<0.001$.

1984, based on two different sampling methods. The first set is derived from the frequencies of male genotypes in table 3 , i.e., the males collected at the same time as the females. Comparing these frequencies with the mean transmitted frequencies in each of the three years shows no significant differences. Despite the heterogeneity in transmission frequency between female genotypes the overall frequency of the transmitted male $F$ allele is the same as it is in adult males. This comparison may not be valid if males suffer selective mortality between mating and the time of sampling - transmitted male allele frequencies should ideally be compared with allele frequencies in mating males. The second set of data in table 5(b) gives estimated frequencies of the $F$ allele in males found in precopula. Again these do not differ significantly from the overall frequency of transmitted $F$ alleles. These last two sets of data serve as an independent test for the absence of male sexual selection. It is clear that allele frequencies in mating males are very close to those amongst all males in the population-none of the comparisons are significant.

\section{DISCUSSION}

The SCA used here has two main drawbacks. First, some of the tests require the acceptance of previous null hypotheses in order to be valid. For instance $T_{2}$ requires that $H_{1}$ be accepted. This does not cause serious problems here because in all three years $T_{1}$ yields no departures from expectation and it is justifiable to proceed to $T_{2}$, the point at which significant departures were detected. Subsequent tests $T_{3}, T_{5}$ and $T_{6}$ require the acceptance of $\mathrm{H}_{2}$ and therefore are not valid in 1983, 1984 and the pooled data. $T_{4}$, the other point at which significant departures were found has no restrictions.

The second problem is that some of the tests confound more than one biological effect. For example, a lack of dependence of transmitted male allele frequency on female genotype (rejection of $\mathrm{H}_{2}$ ) could arise either through non-random mating or through female-specific selection of gametes or of zygotes. The observed low frequency of transmitted (male) $\mathrm{F}$ alleles in progeny of FF mothers could have three different explanations: (a) Fbearing males mate less effectively with FF females, (b) F-bearing sperm have reduced viability in FF females, (c) F-bearing zygotes have lower survival in FF females. Fortunately we can discount the first of these possibilities since an

Table $5 \quad F$ allele frequency in offspring and males

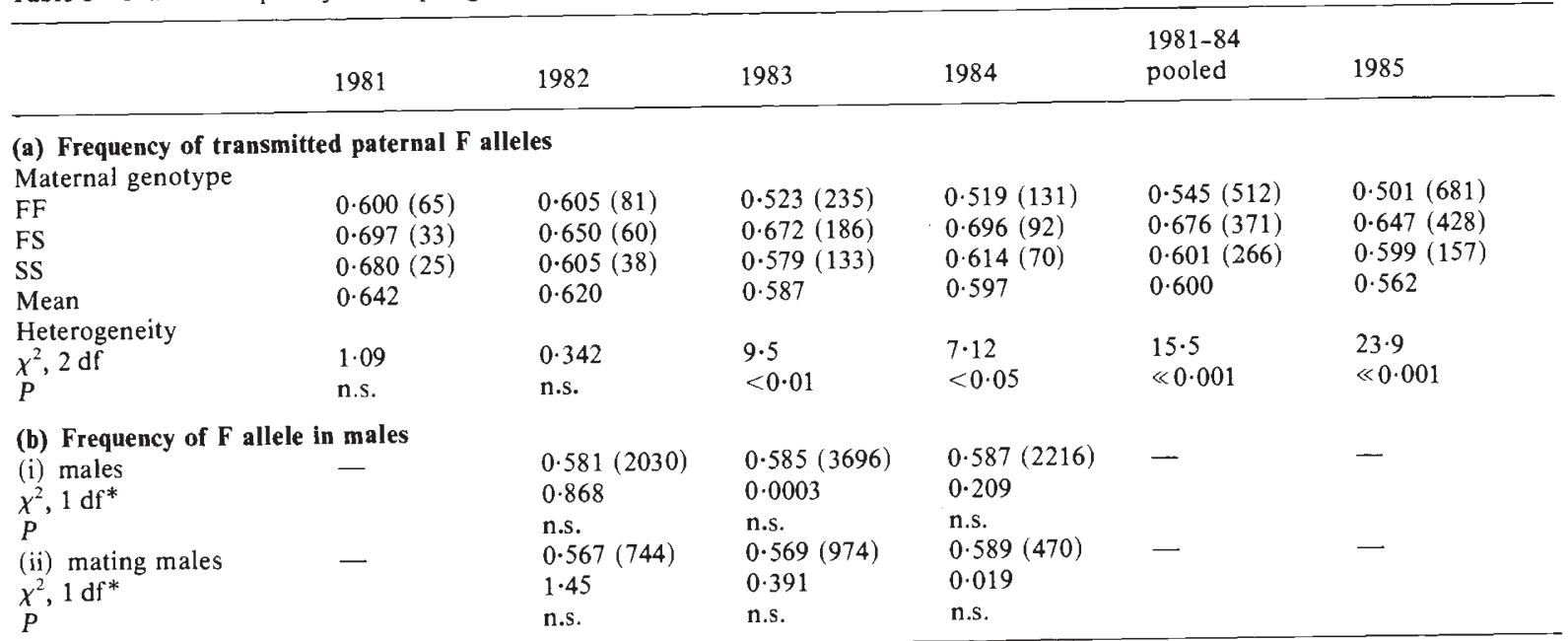

\footnotetext{
* Comparison of $\mathrm{F}$ allele frequency in males with mean transmitted frequency. Figures in parentheses are sample sizes
} 
independent investigation has been conducted of mating pattern with respect to PGI variation. Animals can be collected in precopula and the genotypes of the members of each pair determined. A small survey by Edwards and Heath (1983) showed no departures from random mating and this has been confirmed by Riddoch et al. (1986) using much larger samples. In the latter study animals which were not in precopula were also collected, sexed and genotyped. There was no evidence for differential mating success of males, i.e., genotype frequencies in mating and nonmating males were not different, a result which confirms the non-significant result of $T_{3}$. Neither was there any evidence of differential mating success in females, a result contrary to that described here in $T_{4}$, but this disparity may have arisen because the two approaches use samples taken at slightly different times. Riddoch et al. (1986) drew their samples from the population when the animals were mating. The samples used in the SCA were taken from the population 2-4 weeks later, after mating but before the offspring were released. Equal genotype frequencies among mating and non-mating animals could be converted easily into unequal frequencies among the fertile and non-fertile categories in the SCA by differential mortality.

Given that the female genotype specific differences in transmission rates of male alleles do not arise through non-random mating is it possible to discriminate between the two remaining hypotheses? It could be argued that while femalespecific selection of sperm would have no effect on brood size, selection on zygotes would lead to reduced brood sizes in certain sorts of crosses. For example brood sizes of FF females should be lowest if they have mated with an FF male, highest if the father was SS and intermediate for FS males. This type of effect, known as alloprocoptic selection, has been described by Serradilla and Ayala (1983) for enzyme variability in Drosophila. However, Riddoch (1987) has analysed the relationship between brood size and mating type in this population and finds no such effect. In any case it does not necessarily follow that differential mortality of zygotes in the brood pouch would lead to detectable brood size reduction. All females show brood pouch mortality (Heath and Khazaeli, 1985) with up to 17 per cent of eggs failing to develop into juveniles. In segregating broods it may be that genotypes incompatible with the mother are preferentially lost, but that brood size reductions of similar size also occur in nonsegregating broods.
Whatever the cause of these fitness differences they have two interesting aspects. Firstly they result in no marked deviation in the overall genotype ratios of the offspring. It is only when the results are broken down by maternal genotype that the effects are revealed. This serves to illustrate the dangers of trying to detect selection by merely comparing genotype frequencies in offspring with those in their parents, or those derived from Hardy-Weinberg predictions. Arising from this is the second point of interest, namely that the fitness differences appear to cancel out. The enhanced transmission of $F$ alleles through FS females is compensated for by their reduced transmission through FF females, transmission through SS females occurring at the expected rate. This suggests a mechanism that could lead to a stable polymorphism. If the $\mathrm{F}$ allele were to increase in frequency this would increase the frequency of the FF homozygote. A greater proportion of matings would involve male $\mathrm{F}$ alleles passing through FF females, where their low efficiency of transmission would lead to the frequency of $\mathrm{F}$ falling. Increasing $S$ allele frequency, would have an opposite effect due to the increased frequency of heterozygotes. The system behaves in a similar way to the self incompatibility alleles in plants.

If, as table 5 suggests, the disadvantage to $\mathrm{F}$ alleles in FF females is about equal and opposite to the advantage of $F$ alleles in FS females then the equilibrium point would occur when FF and FS females were in equal proportion, i.e. when the F allele frequency was 0.66 . Eight years data (19791987) are now available on genotype frequencies in this population (Edwards and Heath, 1983; Riddoch 1987; unpublished data). Despite short term fluctuations in frequency within years there is no evidence of any long term change and the mean observed frequency of the F allele is 0.58 .

Allowing for (a) errors (sampling) in the estimation of transmission rates, (b) the advantage (perhaps intermittent) to SS females in sexual selection and (c) the evidence that SS suffer less winter mortality than FS (Edwards and Heath, 1983; Riddoch 1987) the observed and predicted equilibrium frequencies are not that different.

The findings reported here confirm Endler's suggestion (1986) that reproductive components are likely to be important in determining the dynamics of genetic variation in natural populations. The magnitude of the effects also adds weight to his view (p. 208) that generally selection may be more intense on reproductive components than on mortality. If what has been described occurs in the gametic phase then the selective regime will 
be predominantly soft rather than hard. Polymorphisms maintained in this way may be particularly robust and enduring with the consequence that extant polymorphisms may be more likely to owe their existence to these types of selection. Attempts to demonstrate the selective maintenance of polymorphisms which do not investigate these components would have a low probability of success, perhaps explaining the relative rarity of examples of biochemical selection (Endler, p.157).

Acknowledgements This work was supported by a SERC research grant to DJH.

\section{REFERENCES}

BACCUS, R., HILLSTEAD, H. O., JOHNS, P. E., MANLOVE, M. N., MARChINTON, R. L. AND SMITH, M. H. 1977. Prenatal selection in white-tailed deer. 31st Proc. S.E. Assoc. Game and Fish Comm., San Antonio, Texas.

BUNGAARD, J. AND CHRISTIANSEN, F. B. 1972. Dynamics of polymorphisms. I. Selection component analysis in an experimental population of Drosophila melanogaster. Genetics, 71, 439-460.

CHRISTIANSEN, F. B. AND FRYDENBERG, O. 1973. Selection component analysis of natural populations using population samples including mother-offspring combinations. Theor. Pop. Biol., 4, 425-445.
CHRISTIANSEN, F. B., FRYDENBERG, O. AND SIMONSEN, V. 1973. Genetics of Zoarces populations. IV. Selection component analysis of an esterase polymorphism using population samples including mother-offspring combinations. Hereditas, 73, 291-304.

ClEGG, M. T., KAHLER, A. L. AND AllaRD, R. W. 1978. Estimation of life cycle components of selection in an experimental plant population. Genetics, 89, 765-792.

EDWARDS, J. P. 1981. Analysis of an enzyme polymorphism in the isopod Sphaeroma rugicauda (Leach). Ph.D. Thesis, University of Essex.

EDWARDS, J. P. AND HEATH, D. J. 1983. Dynamics of an enzyme polymorphism in the isopod Sphaeroma rugicauda (Leach). I. Temporal variations in genotype frequencies. Heredity, $51,467-475$.

ENDler, J. A. 1986. Natural Selection in the Wild. Princeton University Press, Princeton, New Jersey.

heATH, D. J. AND Khazaeli, A. A. 1985. Population dynamics of the estuarine isopod Sphaeroma rugicauda. Estuarine, Coastal and Shelf Science, 20, 105-116.

NADEAU, J. H. AND BACCUS, R. 1981. Selection components of four allozymes in natural populations of Peromyscus maniculatus. Evolution, 35, 11-20.

RIDDOCH, B. J. 1987. Selection component analysis of the PGI polymorphism in Sphaeroma rugicauda. Ph.D. Thesis, University of Essex.

RIDDOCH, B. J., HEATH, D. J., CHILDS, D. AND RATFORD, J. R. 1986. Mating pattern and PGI variation in a natural population of the isopod Sphaeroma rugicauda (Leach). Biol. Journ. Linn. Soc., 29, 145-148.

SERADILla, J. M. AND AYALA, F. J., 1983. Alloprocoptic selection: A mode of natural selection promoting polymorphism. Proc. Natl. Acad. Sci. USA, 80, 2022-2025.

SIEGISMUND, H. R. 1985. Genetic studies of Gammarus IV. Selection component analysis of the Gpi and Mpi loci in Gammarus oceanicus. Hereditas, 102, 241-250. 